\title{
Să̆ koroner arterin miyokardiyal köprüleşmesi: Olgu sunumu
}

\author{
Myocardial bridging of the right coronary artery: A case report \\ Tolga Aksu, Tolga Çimen, Taner Şen, Mine Koşar Durukan, Ümit Güray, Omaç \\ Tüfekçioğlu
}

Kardiyoloji Kliniği (Dr. T. Aksu), Kocaeli Derince Eğitim ve Araştırma Hastanesi TR-41900 Kocaeli, Kardiyoloji Kliniği (Dr. T. Çimen, Dr. T. Şen, Dr. M. K. Durukan, Doç. Dr. Ü. Güray, Doç. Dr. O. Tüfekçioğlu), Ankara Yüksek İhtisas Eğitim ve Araştırma Hastanesi TR-06230 Ankara

\section{Özet}

Miyokardiyal köprüleşme ana epikardiyal koroner arterlerin birinin miyokard içerisinde seyretmesi durumudur ve genellikle sol ön inen artere sinırlıdır. Anjiyografik değerlendirmede sağ koroner arterde miyokardiyal köprüleşme birkaç kez bildirilmiştir. Biz akut inferiyor miyokardiyal infarktüs kliniği ile başvuran ve yapılan koroner anjiyografisinde sağ koroner arterde ciddi MK saptanan 64 yaşında bir erkek hastayı sunduk.

Anahtar sözcükler: Miyokardiyal köprüleşme, koroner, infarktüs

\begin{abstract}
A myocardial bridge is defined as an intramyocardial course of a major epicardial coronary artery, and it is mainly confined to the left anterior descending coronary artery. There are rare reports of right coronary myocardial bridge seen during angiographic examination. Herein, we present a 64 year-old male patient who appired with the clinical findings of acute inferior myocardial infarction and was found to have serious myocardial bridge in right coranary artery after coranary angiography.
\end{abstract}

Keywords: Myocardial bridge, coronary, infarction

Geliş tarihi/Received: 09 Temmuz 2011; Kabul tarihi/Accepted: 30 Ocak 2012

*İletişim adresi:

Dr. Tolga Aksu, Kardiyoloji Kliniği, Kocaeli Derince Eğitim ve Araştırma Hastanesi, TR-41900 Kocaeli. E-posta: aksutolga@gmail.com

\section{Giriş}

Miyokardiyal köprüleşme (MK) epikardiyal koroner arterlerden birinin bir segmentinin miyokardiyum içerisinde intramural seyretmesi ile karakterize doğumsal bir durumdur [1]. Koroner arterler miyokard içerisinde derinlere doğru değişik uzunluklarda girerler ve tekrar kalp yüzeyinde görünür olurlar. Epikardiyal koroner arterin intramiyokardiyal segmentini örten kas kitlesi miyokardiyal köprü olarak adlandırılır ve miyokard içerisinde seyreden artere tünel arter adı verilir. Sol koroner arterin ön interventriküler dalı MK'nin en sık görüldüğü bölgedir [1]. Bizim vakamız nadir görülen ve sağ koroner arterin tam oklüzyonu neticesinde akut inferiyor miyokardiyal infarktüse neden olan bir $\mathrm{MK}$ vakasidir.

\section{Olgu sunumu}

Altmış dört yaşında hipertansif erkek hasta göğüs ağrısı yakınması ile başvurduğu dış merkezde çekilen EKG'sinde inferoposterolateral miyokard infarktüsü (MI) saptanması 
üzerine streptokinaz tedavisi almıştır. MI sonrası anginal yakınmaları devam eden hasta kurtarıcı perkütan koroner girişim için değerlendirilmek üzere merkezimize kabul edildi. Yapılan koroner anjiyografisinde sağ koroner arter (SKA) proksimalinde \%95'lik darlık izlenirken, SKA'nın arka inen arter dalında sistolde \%100 daralmaya yol açan MK izlendi (Şekil 1 ve 2).

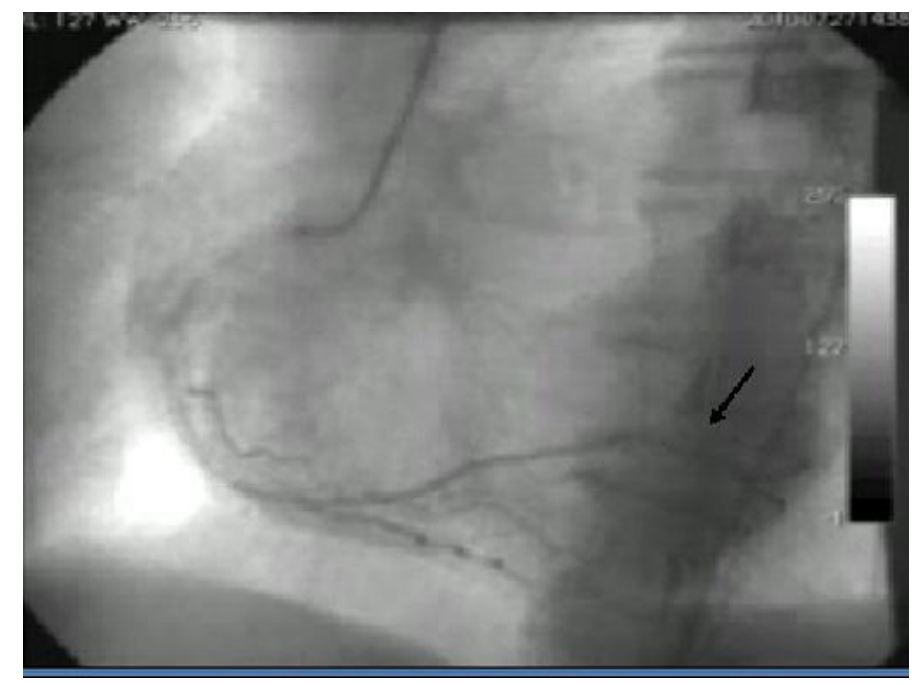

Şekil 1. Sol ön oblik kraniyal görüntülemede sağ koroner arter arka inen dalının (ok) diyastolde tam açık olduğu izlenmekte.

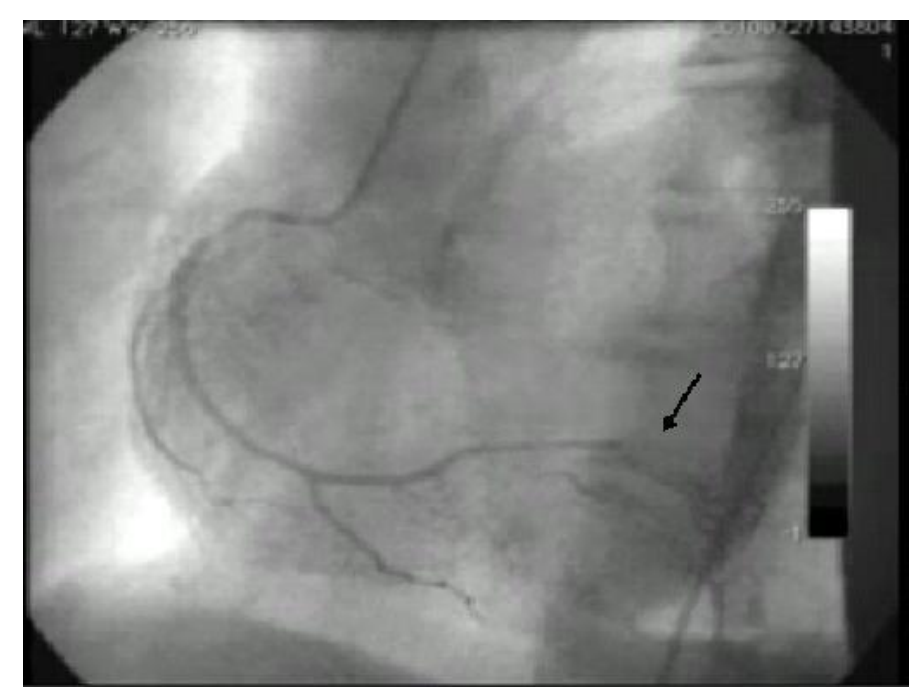

Şekil 2. Sol ön oblik kraniyal görüntülemede sağ koroner arter arka inen dalının (ok) miyokardiyal köprüleşmeye bağlı olarak sistolde tam daraldığı izlenmekte.

SKA'da TIMI 3 akım olması ve sol ön inen arter ve sirkümfleks arterde de ciddi darlıklar olması nedeni ile perkütan koroner girişim yerine cerrahi tedavi uygulanmasına karar verildi. Hastanın operasyon sirasinda koroner anjiyografide belirlenen ile uyumlu olmak üzere SKA distalinde ciddi MK belirlendi safen ven grefti ile komplikasyonsuz koroner baypas cerrahisi uyguland.

\section{Tartışma}

MK ilk olarak 1922 y1lında Crainicianu tarafindan basit bir koroner arter anatomisi varyantı olarak tanımlanmıştır [2]. MK koroner anjiyografik serilerde \%0.5 ile \%12 arasında bildirilmesine rağmen otopsi çalışmalarında \%85'lere varan oranlarda MK varlığından bahsedilmiştir [3]. Otopsi ve anjiyografi serilerindeki sıklıkla ilgili bu 
farklılığın tünelleşen damarın uzunluğu, sistolik kapanmanın derecesi ve kalp hızı ile ilişkili olabileceği bildirilmiştir [4]. Tünelleşen damar segmentinin uzaması, tünelleşen segmentin daralma derecesi ve kalp hızında artış, miyokardiyal iskemiye katkıda bulunmasının yanı sıra MK'nin anjiyografik olarak saptanma şansını da arttırmaktadır. Hastalık asıl olarak sol ön inen arterde görülmekle birlikte literatürde SKA'da MK'nin bildirildiği birkaç vaka da mevcuttur [5, 6]. MK'nin miyokardiyal iskemi için fonksiyonel önemi halen tartışmalı olmasına karşın, angina ve akut MI ile ilişkilendirildiği klinik vakalar mevcuttur [7, 8]. Dahası MK köprüleşen kısmın proksimalinde ateroskleroz gelişimine eğilimi arttırır ve bu yolla koroner arter hastalığı için anatomik bir risk faktörü gibi davranır [4]. Bu yüzden özellikle organik koroner darlığın saptanmadığı hastalarda MK'nin miyokardiyal iskeminin nedeni olabileceği akılda tutulmalıdır. Semptomatik MK'nin tedavisi betabloker ve kalsiyum kanal blokerleri ile kalp hızının düşürülmesi ve kontraksiyon gücünün azaltılmasını içerir. Köprüleşen kısmın serbestleştirilmesini içeren supraarteryel miyotomi semptomların medikal tedavi ile düzelmediği vakalarda alternatif olarak akılda tutulmalıdır [9]. İşlem sonrası düzelme nükleer görüntüleme ve intraoperatif ekokardiyografi ile saptanabilir. Bizim vakamızda MI'dan sorumlu segment olarak SKA proksimali düşünüldüğünden ve MK SKA distalinde olup yalnızca küçük bir alanı beslediğinden cerrahi sırasında bu bölgeye müdahale düşünülmemiştir.

MK genellikle sol ön inen arterde gözükmesine rağmen bizim vakamız gibi bir kaç vakada SKA' da da izlenebilmektedir. MK yalnızca basit bir koroner arter anomalisi olarak değerlendirilmemeli, her vaka klinik ve anjiyografi temelinde bireysel olarak ele alınmalıdır. Bizim vakamızda olduğu gibi ciddi daralma durumlarında kabul edilen tedavi yöntemi halen koroner baypas olmasına rağmen perkütan koroner girişim bir alternatif olarak göz önünde bulundurulmalıdır.

\section{Kaynaklar}

1. Alegria JR, Herrmann J, Holmes DR Jr, Lerman A, Rihal CS. Myocardial bridging. Eur Heart J 2005; 26: 1159-68.

2. Crainicianu A. Anatomische studien über die coronararterien und experimentelle: Untersuchungen über ihre durchgangigkeit. Wrchows Arch Pathol Anat 1922; 238: 1 .

3. Duran C, Kantarc1 M, Durur Subaş1 I, Gülbaran M, Sevimli S, Bayram E, Eren S, Karaman A, Fil F, Okur A. Remarkable anatomic anomalies of coronary arteries and their clinical importance: a multidetector computed tomography angiographic study. J Comput Assist Tomogr 2006; 30: 939-48.

4. De Winter RJ, Kok WE, Piek JJ. Coronary atherosclerosis within a myocardial bridge, not a benign condition. Heart 1998; 80: 91-3.

5. Duygu H, Zoghi M, Kırılmaz B, Türk U, Akıllı A. Myocardial bridgings of the right coronary artery and left anterior descending coronary artery: very unusual form of myocardial bridge. Anadolu Kardiyol Derg 2005; 5: 342.

6. Kulkarni M, Sodani A, Rosita, Puranik C, Sullere S, Saha B. Right myocardial bridge on CT coronary angiography. J Assoc Physicians India 2004; 52: 661-2.

7. Bestetti RB, Costa RS, Zucolotto S, Oliveira JS. Fatal outcome associated with autopsy proven myocardial bridging of the left anterior descending coronary artery. Eur Heart J. 1989; 10: 573-6.

8. Akdemir R, Gündüz H, Emiroğlu Y, Uyan C. Myocardial bridging as a cause of acute myocardial infarction: a case report. BMC Cardiovasc Disord 2002; 2: 15.

9. Downar J, Williams WG, McDonald C, Wigle ED, McCrindle BW. Outcomes after "unroofing" of a myocardial bridge of the left anterior descending coronary artery in children with hypertrophic cardiomyopathy. Pediatr Cardiol 2004; 25: 390-3. 